\title{
A superior thermostable and nonflammable composite membrane towards high power battery separator
}

\author{
Bo Zhang, Qingfu Wang, Jianjun Zhang, Guoliang Ding, Gaojie Xu, \\ Zhihong Liu, Guanglei Cui*
}

\author{
Qingdao Industrial Energy Storage Technology Institute, Qingdao Institute of Bioenergy and Bioprocess \\ Technology, Chinese Academy of Sciences, Qingdao 266101, PR China
}

Received 24 June 2014; received in revised form 16 September 2014; accepted 1 October 2014

Available online 12 October 2014

\section{KEYWORDS}

Glass microfiber;

Polyimide;

Separator;

Nonflammable

\begin{abstract}
The composite membrane of glass microfiber and polyimide was prepared by paper making method and following dip-coating process to explore the feasibility as high performance separator of lithium ion battery (LIB). It was demonstrated that the composite membranes, with a thickness of about $45 \mu \mathrm{m}$, possessed a significantly enhanced tensile strength and a modified porous structure, compared with that of pristine glass microfiber membrane. Impressive improvements in thermostability and flame retarding were achieved for composite membrane, with no shrinkage at the elevated temperature of $200^{\circ} \mathrm{C}$, even no burn on fire, compared with commercial polyolefin separators. Meanwhile, the composite membrane presented a favorable wettability and remarkable electrochemical stability in commercial liquid electrolyte. In addition, the battery test results of $\mathrm{LiFePO}_{4} / \mathrm{Li}$ and $\mathrm{LiFePO}_{4} /$ graphite cells proved the composite membrane was a promising separator with an improved rate capability. The cycle performance of cells at the elevated temperature of $120{ }^{\circ} \mathrm{C}$ demonstrated their excellent safety characteristic as separator in LIB, indicating the composite membrane was a potential separator candidate for high power battery.

(c) 2014 Elsevier Ltd. All rights reserved.
\end{abstract}

\section{Introduction}

In recent years, lithium ion battery (LIB) has been considered as a promising candidate for high power battery in electric

*Corresponding author. vehicles (EV) and hybrid electric vehicles (HEV) [1]. The safety issue of battery, however, becomes a critical feature in EV and HEV. The most of unsafe events are caused by the internal short-circuit, which is derived from poor dimensional thermostability of separator. In LIB, the separator is sandwiched between the cathode and the anode that prevents physical contact of the electrodes while enabling free ionic transport 
and isolating electronic flow [2]. Therefore, the separator should be tolerant for chemical and electrochemical interaction from the electrolyte and electrode materials, and mechanically strong to deal with collision and stretching during battery manufacturing. Moreover, the separator should also have sufficient porosity to absorb liquid electrolyte for high ionic conductivity [3]. Now the commercial separator are porous polyolefin membranes, such as polypropylene (PP) and polyethylene (PE) membranes, due to their fair mechanical properties and chemical stability [4].

However, these porous polyolefin membranes also have their drawbacks. The low porosity derived from their semicrystalline structure and melt blowing technology, together with poor wettability caused by their hydrophobic nature, lead to an increased cell resistance $[5,6]$. More importantly, these membranes have been proven to suffer from poor dimensional thermostability at elevated temperature, due to the intrinsic melting characteristic $\left(\mathrm{PE} / 130^{\circ} \mathrm{C}, \mathrm{PP} / 165^{\circ} \mathrm{C}\right)$ [7]. For this reason, the separator cannot guarantee the safety of battery at extreme conditions, such as heating, abuse and overcharge. And more seriously, flammable separators may intensify the deterioration. As has been reported, extensive efforts thus have been directed to solve the poor thermostability of separator, such as silica nanoparticle enhanced polysulfonamide nonwoven separator, non-woven mats and ceramic particles, porous polyimide separator, polyimide-coated PET nonwoven membranes and poly(phthalazinone ether sulfone ketone) (PPESK) separator [8-14]. All these separator exhibited good dimensional thermostability, but none of them can retard the combustion of separator at elevated temperatures. In addition, these high performance polymer separator is too expensive for large-scale application in LIB.

non-carbon ingredients, for instance, glass microfiber [15]. But, the commercial membrane of glass microfiber suffers from poor mechanical performance for battery assembling, and large pores more than $1 \mu \mathrm{m}$, which is prone to generate electric leakage. Therefore most of their film demands a thickness more than $1 \mathrm{~mm}$ to guarantee the safety issues for application in cells, which alleviate the volume energy density of cells (Supplementary SI. 1). The mechanical punching method can be favorable to decrease the thickness, but break down the fiber simultaneously (Supplementary SI. 2), which is bad choice to improve the overall performance. Therefore, in this study a thin film of glass microfiber was prepared by paper-making method, and incorporated with polyimide by a dip-coating process to enhance its mechanical strength and physical performance. Our results demonstrate that composite membrane is a very promising separator to significantly improve the safety issue of LIB, owing to its excellent dimensional thermostability and nonflammable property. Furthermore, our work presents the feasibility of inorganic glass microfiber composite to solve the safety issues of high power LIB, comparing to commercial PP separator.

\section{Material and methods}

\section{Materials}

Glass microfiber $(1.0-3.5 \mu \mathrm{m})$ was supplied by Johns Man ville (USA). The poly(amic acid)(PAA) was prepared via in situ polymerization by pyromellitic dianhydride(PMDA) and 4,4-oxidianiline(ODA). PMDA, ODA, and N,N-dimethylacetamide (DMAC) were purchased from Sigma-Aldrich(USA). All chemicals were used as received without further purification. Celgard 2400 (PP, Celgard Company) separator was chosen for comparison.

\section{Polymer synthesis}

The poly(amic acid)(PAA), the precursor of polyimide ( $\mathrm{PI})$, was prepared via in situ polymerization from PMDA and ODA by the following procedure. The ODA $(8.8993 \mathrm{~g}, 20 \mathrm{mmol})$ and anhydrous DMAC $(66.93 \mathrm{~g}, 76 \mathrm{~mL})$ were fitted into a dried $250 \mathrm{~mL}$ three-necked flask equipped with a mechanical stirrer, a nitrogen inlet, and a thermometer. Then PMDA $(8.0096 \mathrm{~g}, 20 \mathrm{mmol})$ was added to the solution gradually. The molar ratio of PMDA to ODA was 1:1. After polymerization for $6 \mathrm{~h}$ at $0{ }^{\circ} \mathrm{C}$, the reactant mixture became sticky and transferred into a container stored in refrigerator.

\section{Fabrication of membrane}

The membrane of glass microfiber was fabricated through a paper making process of suction filtration. The details can be found in literature $[16,17]$. Compared to the commercial glass microfiber membrane (more than $1 \mathrm{~mm}$ ), the obtained glass microfiber film was as thin as about $45 \mu \mathrm{m}$.

A series of glass microfiber and polyimide composite membranes were prepared by a dip-coating process from PAA solutions with different solid contents. At first, the PAA was dissolved in DMAC, and then filtered using a ceramic filter and degassed. After that, the polyimide solution was casted on the membrane of glass microfiber, followed by a gradual drying process at $60^{\circ} \mathrm{C}$ for $30 \mathrm{~min}, 120^{\circ} \mathrm{C}$ for $30 \mathrm{~min}, 200^{\circ} \mathrm{C}$ for $1 \mathrm{~h}$, to remove the residual solvent. Finally, the thermal imidization of polyimide was carried out at an elevated temperature of $300{ }^{\circ} \mathrm{C}$ for $3 \mathrm{~h}$. The composite membranes prepared from the polyimide solutions with solid content of 0 , 5 , 10, and $20 \mathrm{wt} \%$ were defined as GF, GPI-5, GPI-10, and GPI-20, respectively. The average thickness of these GPI membranes was in the range of $45 \pm 1 \mu \mathrm{m}$.

\section{Characterization}

The X-ray diffraction (XRD) pattern of GPI membranes were measured by a diffractometer (Bruker D8 ADVANCE) using a $\mathrm{Cu} K \alpha$ radiation $(\lambda=1.5406 \AA)$. The infrared spectrum (IR) was recorded on a Perkin-Elmer 782 Fourier transform spectrophotometer. SEM imaging of the films were taken by FE-SEM HITACH S4800 with operating voltage of $3.0 \mathrm{kV}$.

The porosity of composite membranes was determined using $n$-butanol uptake method and then calculated using Eq. (1):

Porosity $=\left(m_{b} / \rho_{b}\right) /\left(m_{b} / \rho_{b}+m_{a} / \rho_{a}\right) \times 100 \%$

where $m_{a}$ and $m_{b}$ are the mass of composites and $n$-butanol, the $\rho_{a}$ and $\rho_{b}$ are the density of composite material and $n$ butanol. The electrolyte uptake was measured by the weight of composite membranes with a certain area before and after liquid electrolyte (1 M lithium hexafluorophosphate $\left(\mathrm{LiPF}_{6}\right)$ dissolved in $1 / 1(\mathrm{~V} / \mathrm{V})$ ethylene carbonate (EC)/dimethyl carbonate (DMC)) soaking for $0.5 \mathrm{~h}$ at $25^{\circ} \mathrm{C}$ 
and then calculated using Eq. (2):

Electrolyteuptake $=\left(W_{f}-W_{i}\right) / W_{i} \times 100 \%$

where $W_{i}$ and $W_{f}$ are the mass of the composite membranes before and after immersion in electrolyte, respectively. The Gurley value of the composite membranes were examined by a Gurley-type densometer ( 4110 N, Gurley) by measuring the time necessary for air to pass through a determined volume $\left(100 \mathrm{~cm}^{3}\right)$ under a given pressure. The thermal properties of the membranes were evaluated after stored at $150{ }^{\circ} \mathrm{C}$ and $200{ }^{\circ} \mathrm{C}$ for $0.5 \mathrm{~h}$, respectively.

Electrochemical stability of composite membranes were evaluated by linear sweep voltammetry (LSV). The membrane was sandwiched between a stainless steel working electrode and a lithium metal electrode as both the counter and reference electrode. The $\mathrm{CHI} 600 \mathrm{E}$ system (Chenhua, Shanghai) was used to record the electrochemical stability and the voltage was swept at a scan rate of $1 \mathrm{mV} \mathrm{s}^{-1}$ in the range of 2.5-6.0 $\mathrm{V}$ versus $\mathrm{Li}^{+} / \mathrm{Li}$ at room temperature. A solution of $\mathrm{EC}$ and DEC (1/1 in $v / v)$ containing $1 \mathrm{M} \mathrm{LiPF}_{6}$ was used as liquid electrolyte. Ionic conductivity of membranes was determined by electrochemical impedance spectroscopy (EIS) using a Zahner system. The liquid electrolyte-soaked membranes were sandwiched between two stainless-steel plate electrodes and the spectra were recorded in a frequency range of $1-10^{6} \mathrm{~Hz}$ with an AC amplitude of $20 \mathrm{mV}$ at room temperature. The bulk resistance of membranes were determined from the impedance spectrum. The ionic conductivity was calculated from Eq. (3):

$\sigma=d / R_{b} S$

where $\boldsymbol{R}_{\boldsymbol{b}}$ is the bulk resistance, $\boldsymbol{d}$ and $\boldsymbol{S}$ are the thickness and area of the composite membrane, respectively.
Battery performance of composite membranes as separator of lithium ion cell was investigated by half-cell method. The CR2032 coin cell was assembled by sandwiching the membrane between a $\mathrm{LiFePO}_{4}$ cathode and a $\mathrm{Li}$ anode or graphite anode, and then activated by filling the liquid electrolyte (1 $\mathrm{M} \mathrm{LiPF}_{6}$ in $\left.\mathrm{EC} / \mathrm{DEC}\right)$ at room temperature. The $\mathrm{LiBOB} / \mathrm{PC}$ was chosen for an elevated temperature test. All assembly of cells was carried out in an argon-filled glove box. The charge-discharge capacity of cell was evaluated with a battery testing system (CT2001A, Wuhan Land Electronics Co., China) under a constant current mode of $0.2 \mathrm{C}$ rate in the voltage range of $2.8-4.2 \mathrm{~V}$ at room temperature and the elevated temperature of $120^{\circ} \mathrm{C}$.

\section{Results and discussion}

\section{Structure and synthesis}

The polyimide was synthesized via one-pot solution polycondensation at low temperature in DMAc and following thermal imidization as shown in Fig. 1a. It was reported that the low temperature polycondensation was prone to synthesize high molecular weight polyimide, because the polycondensation was an exothermic reaction [18]. Another critical factor in polymerization is water-free, which caused the precipitation of PAA. An uninterrupted nitrogen passing through the reaction tank was necessary to take away the water vapor produced by polymerization.

The IR spectrum of polyimide before and after imidization was descripted as Fig. 1b, in which the characteristic absorption peak of amide carbonyl were observed at about
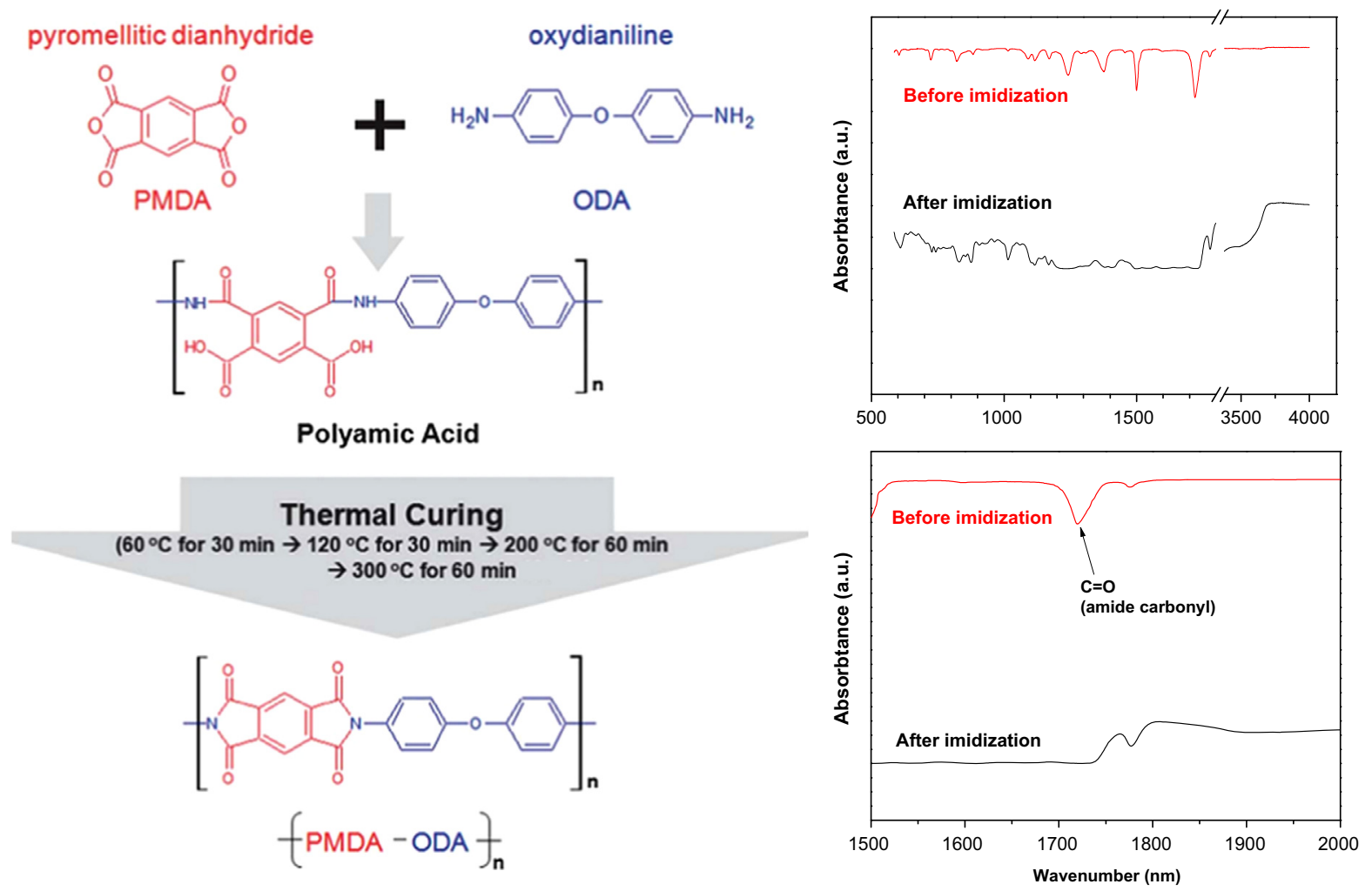

Fig. 1 A scheme for synthesis of polyimide: (a) the polymerization and imidization of polyimide, (b) FT-IR spectra of polyimide before and after imidization, (c) the enlarged details of (b). 
$1724 \mathrm{~cm}^{-1}$ for PAA. After thermal imidization, the infrared absorption characteristic peaks transferred to $1780 \mathrm{~cm}^{-1}$, which indicated the imidization of PI. This alternation in IR spectrum was in agreement with the Refs. $[19,20]$.

The crystal structure and element composition was the first step to make clear the glass microfiber membrane. It was obviously observed that the glass microfiber was composed of amorphous silicon dioxide, calcium oxide, as depicted as XRD and EDX spectrum (Supplementary SI. 3). With the increasing PAA solution concentration, the diffraction peaks of composite became sharp, and the full width at half maximum (FWHM) of diffraction peak became narrower, suggesting an improved crystallinity of composite membranes. The better crystallinity can be ascribed to the generation of crystallized polyimide after imidization, according to previous literatures [21,22].

The morphology of membranes were closely related to the performance of separator in battery. The SEM images with low and high magnification were shown in Fig. 2 and Supplementary SI. 4, respectively. As described in Fig. 2a, the glass microfiber was crossed and stacked with each other to form a nonwoven film with loose structure, which was a typical feature of papermaking process. The average diameter of glass microfiber was $3.1 \mu \mathrm{m}$, and there were many large-sized pores distributed among glass microfibers. In general, the large-sized pores is prone to cause a risk of short-circuit for cells due to self-discharge and instability at high rate discharge.

For the composite membranes, the PAA solution with 5, 10 and $20 \mathrm{wt} \%$ of solid content was used as casting precursor, respectively, as shown in Fig. 2b-d. It was observed that the polyimide preferred to coat on the surface of fiber at low solution concentrations, owing to a good compatibility between them. With increasing PAA concentrations, it started to inter-connect the neighbor microfibers by filling the pores among microfibers. It was obvious that the incorporation of polyimide into glass microfiber nonwovens were favorable to tune the porous structure and improve the mechanical performance due to the induction of highstrength polyimide.

\section{Mechanical and physical properties of membranes}

The tensile strength-strain curves of composite membranes were shown in Fig. 3. For the pristine glass microfiber film, the tensile strength was as low as $1.1 \mathrm{MPa}$, which was far away from the requirements of battery assembling. The

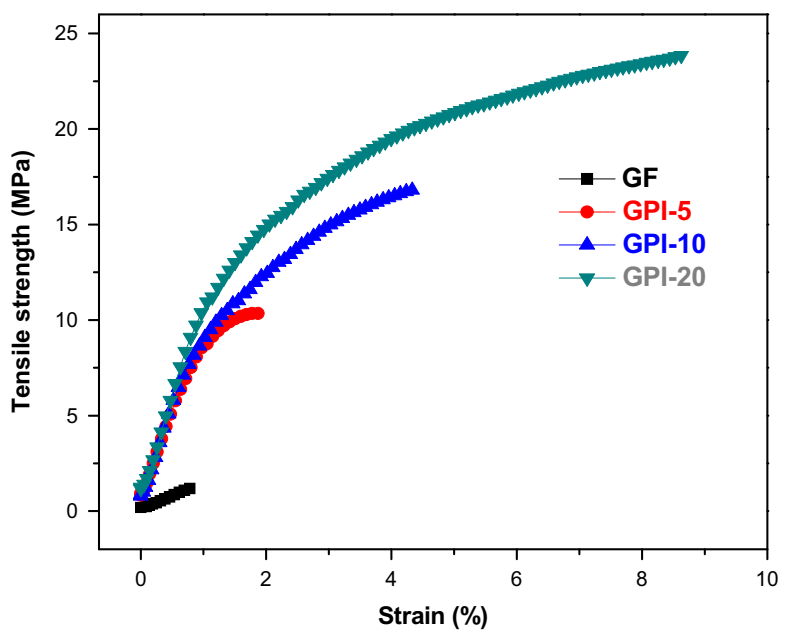

Fig. 3 The stress-strain curves for composite membranes with different PAA concentrations.
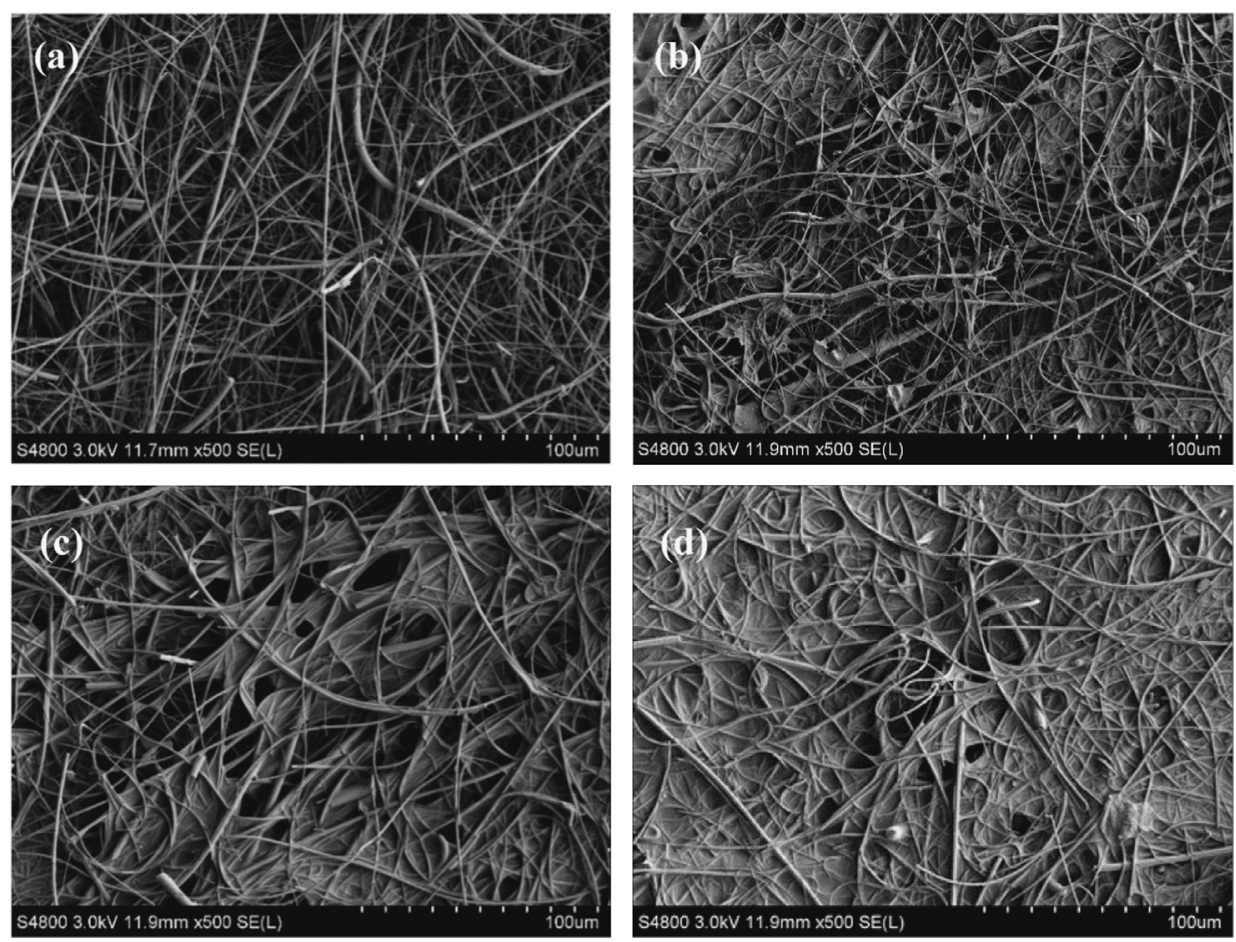

Fig. 2 The SEM images of composite membranes with different PAA concentrations (a) GF, (b) GPI-5, (c) GPI-10, (d) GPI-20. 
tensile strength increased linearly with the rising PAA concentrations, about $10.4 \mathrm{MPa}$ for GPI-5, $16.1 \mathrm{MPa}$ for GPI-10 and 23.8 MPa for GPI-20, respectively. The improvement of tensile strength was closely linked to the high mechanical feature of polyimide with oriented crystallization after imidization, which tensile strength of polyimide films with biaxially oriented method was reported up to 164.3 MPa [23]. Therefore, these results suggested that the incorporation of polyimide was an effective way to enhance the mechanical performance of glass microfiber membrane.

From the view of separator, the porosity of membrane was a practical feature, which provided the channel for ionic transport. The porosity and other physical characteristics of composite membrane with different PAA concentrations and the commercial separator (Celgard 2400) was listed by Table 1, [24]. It can be found that many parameters of GPI-5 membrane were close to that of commercial separator. Therefore, GPI-5 membrane, which was chosen as the representative of composite membrane, and the glass microfiber (GF), in comparison with commercial separator (Celgard 2400, PP), were selected for testing in the following work.

The dimensional thermostability of membranes was one of the most important factors of the separator for battery safety. It was considered that its thermostability of membranes was affected by the chemical structure. In the thermal shrinkage evaluation, the GF, GPI-5 and PP membranes were stored in an oven for $30 \mathrm{~min}$ in air at 150 and $200{ }^{\circ} \mathrm{C}$, respectively. Fig. 4 showed the photographs of membranes before and after thermal shrinkage test at different temperatures. It can be seen that the Celgard 2400 membrane exhibited a significant shrinkage after storage at $150{ }^{\circ} \mathrm{C}$, and changed the color of white to semi-transparent due to the partial melting of membrane. As the temperature further increased to $200{ }^{\circ} \mathrm{C}$ (higher than melting point of PP, $166^{\circ} \mathrm{C}$ ), the Celgard 2400 membrane melted completely [25]. In contrast, almost no obvious shrinkage and the color change were observed for GF and GPI-5 membranes after storage at the temperature of $200{ }^{\circ} \mathrm{C}$. The thermal shrinkage ratio of the membranes was determined by the area changes of sample after subjected at different temperature. From the results summarized in Table 2, it was noted that the Celgard 2400 membrane showed a significant thermal shrinkage $32 \%$ at temperature $150{ }^{\circ} \mathrm{C}$, while the GF and GPI-5 membrane showed no dimensional changes. Therefore, from the viewpoint of the dimensional thermostability, it could be expected that the composite membrane would provide the excellent safety characteristic for high power battery even at elevated temperatures.

The nonflammable property of separator was so crucial that it could terminate further fire or other accident in abuse condition. The combustion test of the membranes was shown in Fig. 5. When the commercial separator of Celgard 2400 was put on the fire, the separator melt down immediately and caught fire in a short time $(<2 \mathrm{~s})$ due to the existence of combustible polyolefin matrix (Fig. 5c). The GF membrane showed per fect flame retarding ability, because the components in GF membrane were $\mathrm{SiO}_{2}$ and $\mathrm{CaO}$, which was incombustible material (Fig. 5a). The GPI-5 membrane did not catch on fire

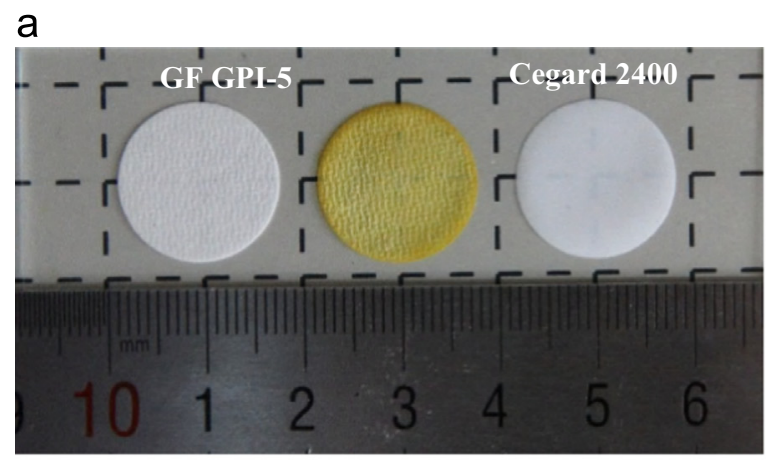

b

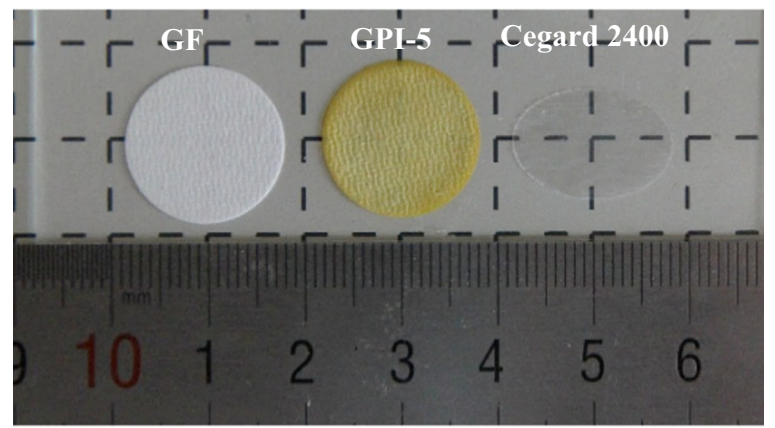

C

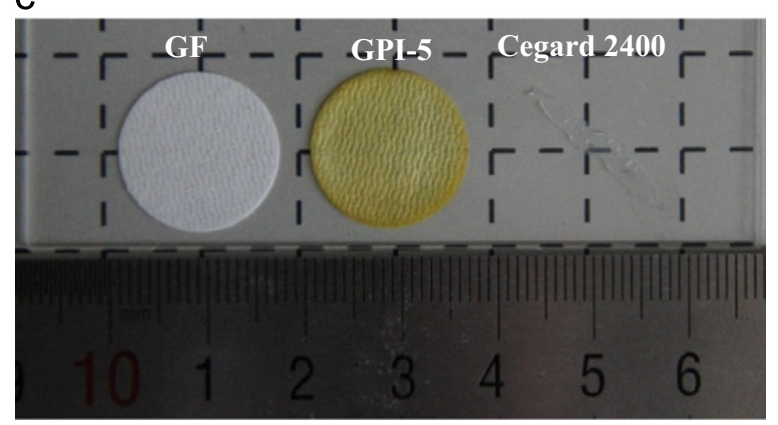

Fig. 4 Photographs of GF, GPI-5 membrane and Celgard 2400 separator at different temperature (a) room temperature, (b) at $150{ }^{\circ} \mathrm{C}$ for $30 \mathrm{~min}$, (c) at $200^{\circ} \mathrm{C}$ for $30 \mathrm{~min}$.

Table 1 Porosity and other physical properties of composite membrane with different PAA concentrations.

\begin{tabular}{lllcl}
\hline Sample & Thickness $(\mu \mathrm{m})$ & Porosity $(\%)$ & Gurley value $\left(\mathrm{s} / 100 \mathrm{~cm}^{3}\right)$ & Density $\left(\mathrm{g} \mathrm{cm}^{-3}\right)$ \\
\hline GF & 45 & 73 & 126 & 0.41 \\
GPI-5 & 46 & 49 & 295 & 0.56 \\
GPI-10 & 44 & 28 & 923 & 0.73 \\
GPI-20 & 46 & 13 & $>1000$ & 1.08 \\
Celgard 2400 & 25 & 42 & 610 & 0.60 \\
\hline
\end{tabular}


Table 2 Physical properties of glass microfiber, composite membrane and Celgard 2400 separator.

\begin{tabular}{|c|c|c|c|c|c|c|}
\hline Sample & $\begin{array}{l}\text { Thickness } \\
(\mu \mathrm{m})\end{array}$ & $\begin{array}{l}\text { Porosity } \\
\text { (\%) }\end{array}$ & $\begin{array}{l}\text { Gurley value (s/ } \\
100 \mathrm{~cm}^{3} \text { ) }\end{array}$ & $\begin{array}{l}\text { Bulk resistance } \\
(\Omega)\end{array}$ & $\begin{array}{l}\text { Electrolyte uptake } \\
\text { (\%) }\end{array}$ & Thermal shrinkage (\%) \\
\hline GF & 45 & 73 & 126 & 1.8 & 300 & \multirow{3}{*}{$\begin{array}{l}\text { Non } \\
\text { Non } \\
32 / 150{ }^{\circ} \mathrm{C} \text {, Melted } \\
/ 200^{\circ} \mathrm{C}\end{array}$} \\
\hline GPI-5 & 46 & 49 & 295 & 2.8 & 210 & \\
\hline $\begin{array}{l}\text { Clegard } \\
2400\end{array}$ & 25 & 42 & 610 & 3.8 & 120 & \\
\hline
\end{tabular}

a

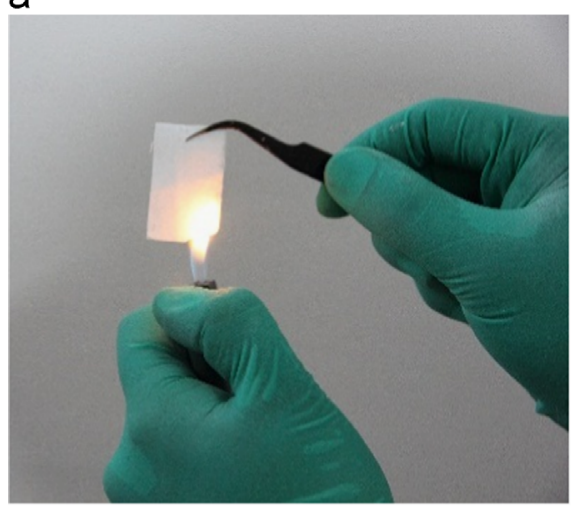

C

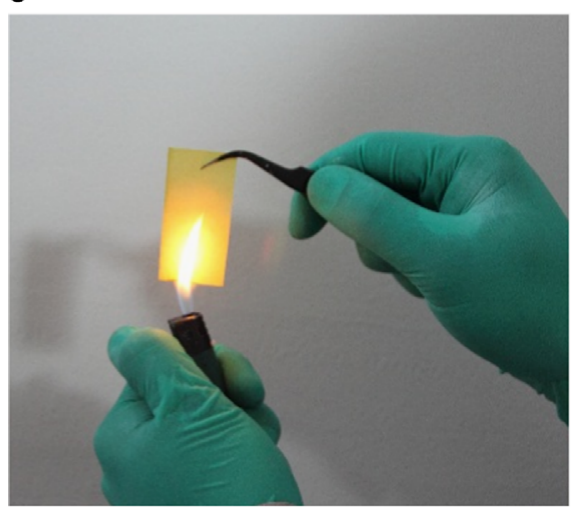

e

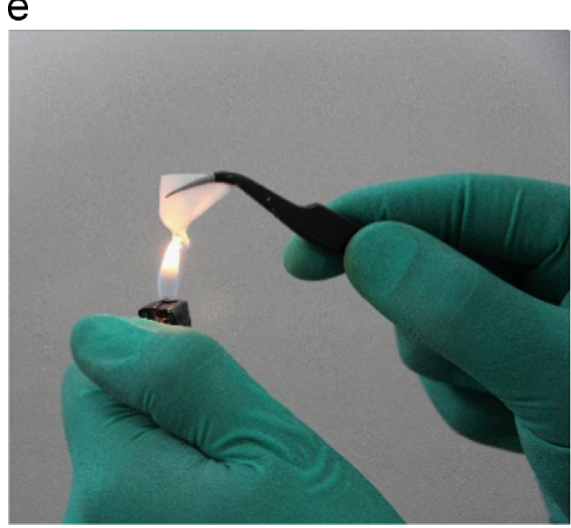

b

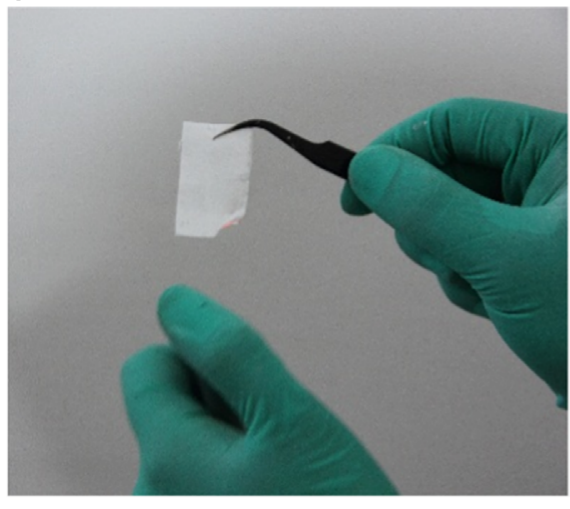

d

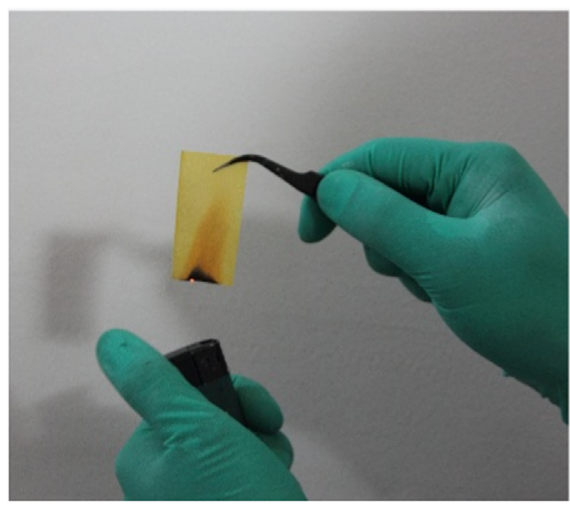

f

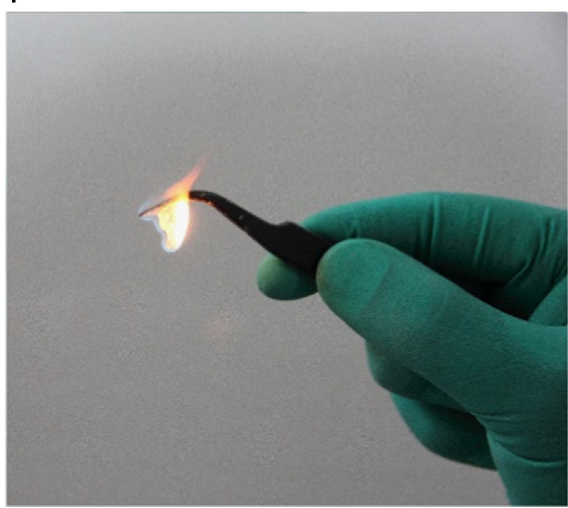

Fig. 5 The flame retarding behavior of GF, GPI-5 membrane and Celgard 2400 separator ( $a$ and b) GF membrane, (c and d) GPI-5 membrane, (e and f) Celgard 2400.

and also no shrinkage when putting on the fire (Fig. 5b). The color of the GPI-5 membrane turned black indicating the carbonization of polyimide after combustion. The super nonflammable property of GPI-5 membranes proved that it was a perfect candidate for high performance separator, to guarantee improved safety characteristic of battery. 


\section{Interfacial characterization of membranes in liquid electrolyte}

The wettability of separator was an important factor affecting performance of battery. The wettability of the samples was evaluated by spreading test and water contact angle measurement to evaluate their surface characteristic [26]. In the spreading test, the electrolyte was dipped on the membranes and then observed its spreadability. As shown in Fig. $6 a$ and b, the electrolyte was sucked up, and spread over the membranes rapidly. The electrolyte spread to the whole membranes of GF and GPI- 5 in no more than $10 \mathrm{~s}$. As comparing to these membranes, the Clegard 2400 membrane kept the electrolyte in the form of liquid droplet on the surface, and indicating that it was hard for electrolyte to spread or diffuse into the membrane. The water contact angle of GPI-5 and Celgard 2400 membrane was $83.5^{\circ}$ and $108^{\circ}$, while that of GF was unable to capture due to a fast wetting process on the surface. These results also indicated a poor wetting performance of Clegard 2400 membrane, compared with GF and GPI-5. The poor wetting performance of Clegard 2400 membrane could be ascribed to its intrinsically hydrophobic nature and low surface energy of PP [27]. The wetting property of these membranes was further examined by electrolyte uptake, as shown in Table 1. The electrolyte uptake was determined by

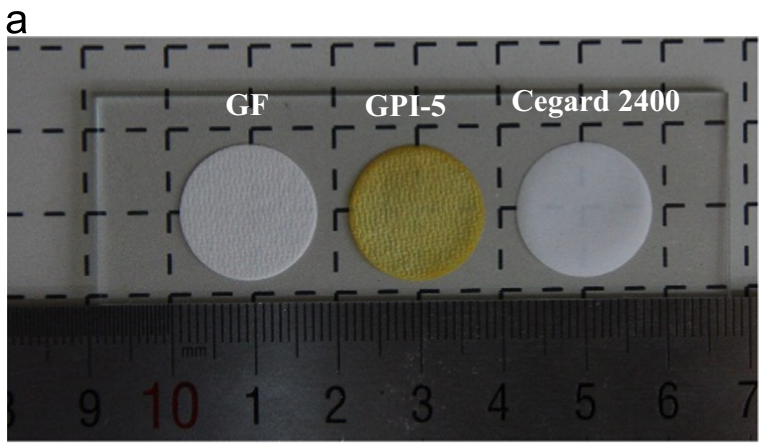

b
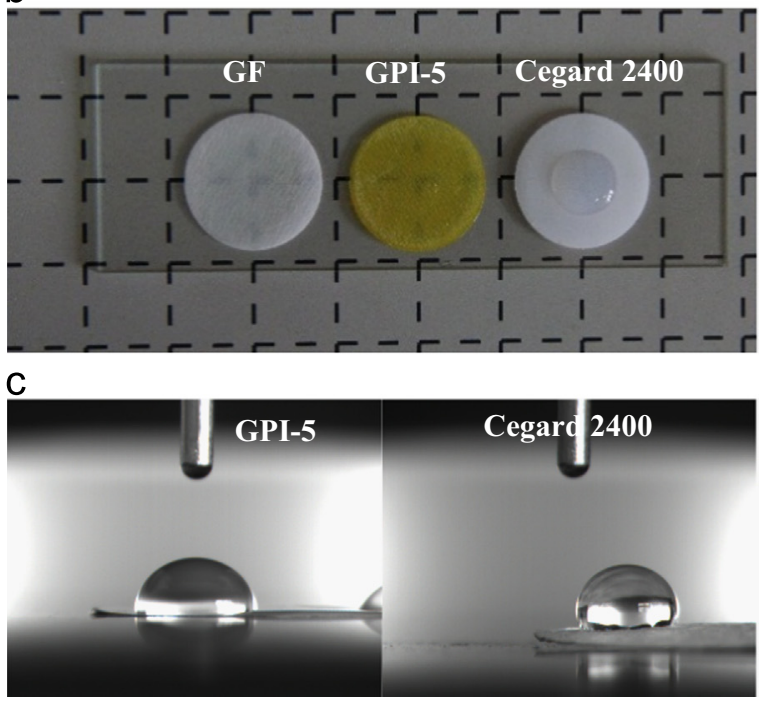

Fig. 6 The wetting behavior of GF, GPI-5 membrane and Celgard 2400 separator for liquid electrolyte (1 M LiPF 6 in EC/ $D M C=1 / 1 \mathrm{v} / \mathrm{v}$ ) and water contact angle (a) before dipping, (b) after dipping, (c) water contact angle. weighing the changes of membranes before and after immersion in liquid electrolyte solution of $1 \mathrm{MLiPF}_{6}$ in EC/DEC for $1 \mathrm{~h}$ until saturation. The electrolyte uptake of GF, GPI-5 and Celgard 2400 membranes was $300 \%, 210 \%$ and $120 \%$, respectively. The superior liquid electrolyte wettability was resulted from the hydrophilic surface and high porosity of membrane, both of which facilitated the capillary intrusion of the liquid electrolyte into the membrane [28].

The chemical stability of membranes in electrolyte ensured the reliability of separator in LIB. The electrochemical window of membranes soaked in liquid electrolyte, was evaluated by linear sweep voltammetry (LSV) experiment at room temperature. As shown in Fig. 7, there was no obvious decomposition of electrolyte in the membranes taking place below $4.5 \mathrm{~V}$, which was in agreement with previous literature [29]. It was found that the GF and Celgard 2400 membranes exhibited anodic stability up to $4.5 \mathrm{~V}$ versus $\mathrm{Li}^{+} / \mathrm{Li}$, while $\mathrm{GPI}-5$ membrane was more than $4.7 \mathrm{~V}$. These results indicated that polyimide could enhanced the interface compatibility in the electrolyte than glass microfiber and PP, which was in accordance with previous report of porous polyimide membrane with an electrochemical stability up to $5.0 \mathrm{~V}$ [30]. It was deduced that the introduction of polyimide was favorable to improve the interfacial stability in the electrolyte. Therefore, the composite membrane may be a potential separator for a high voltage battery application.

The ionic conductivity of membranes were determined by electrochemical impedance spectroscopy and that of Celgard 2400 membrane was also done for a fair comparison. Fig. 8 presented the Nyquist plots of the electrochemical impedance for the liquid electrolyte-soaked GF, GPI-5 and Celgard 2400 membranes. The bulk resistance of the membranes could be determined by the intercept of plots on the real axis. It can be seen that the GF and GPI- 5 membranes showed a relative low bulk resistance than Celgard 2400 membrane. The ionic conductivity of membranes were calculated to be $0.45,0.38$ and $0.31 \mathrm{mS} \mathrm{cm}^{-1}$ for GF, GPI-5 and Celgard 2400 membranes, respectively. From Table 1, the results showed the same trend in the case of porosity and electrolyte uptake, which suggested that the high porosity kept more

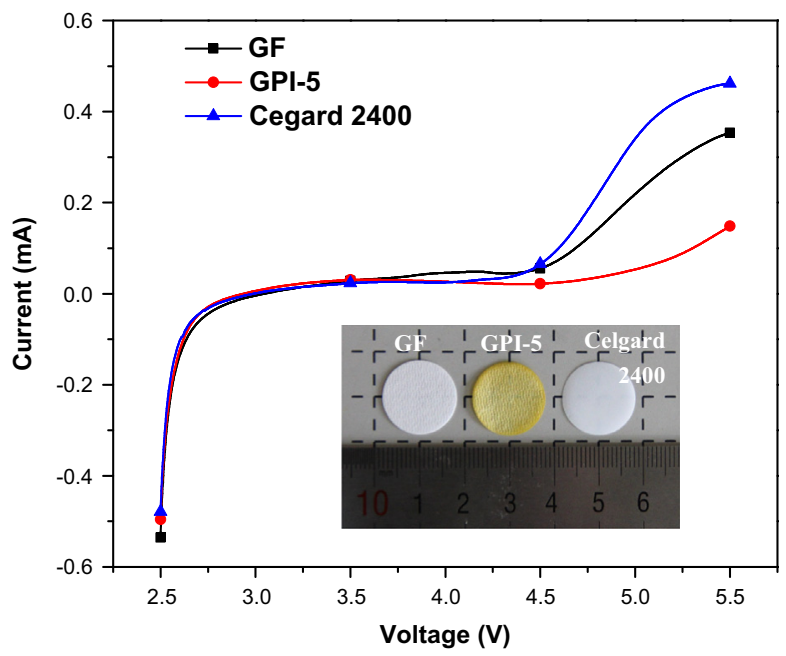

Fig. 7 The linear sweep voltammograms of GF, GPI-5 membrane and Celgard 2400 separator in the electrolyte of $1 \mathrm{M} \mathrm{LiPF}_{6}$ in $\mathrm{EC} / \mathrm{DMC}$. 
liquid electrolyte in the membrane and resulted in an enhanced the ionic conductivity of the electrolyte system [31].

\section{Cell performance of membranes as separator}

The battery performance is a direct way to evaluate separator in LIB. The cycle life of lithium ion cells with GF, GPI-5 membranes and Celgard 2400 membranes as separator was investigated, as shown in Fig. 9. It was found that the first discharge capacity of $\mathrm{LiFePO}_{4} / \mathrm{Li}$ cells from 2.8 to $4.2 \mathrm{~V}$ were $131 \mathrm{~mA} \mathrm{~h} \mathrm{~g}^{-1}, 143 \mathrm{~mA} \mathrm{~h} \mathrm{~g}^{-1}$, and $142 \mathrm{~mA} \mathrm{~h} \mathrm{~g}^{-1}$ at $0.2 \mathrm{C} / 0.2 \mathrm{C}$ for GF, GPI-5 and Celgard 2400 separator, respectively. After 100 cycles, this discharge capacity reduced to $104 \mathrm{~mA} \mathrm{~h} \mathrm{~g}^{-1}$ with GF, $123 \mathrm{mAh} \mathrm{g}^{-1}$ with GPI-5, $112 \mathrm{mAhg}^{-1}$ with Cel gard 2400 separator. The similar results were also observed in the case of $\mathrm{LiFePO}_{4} /$ graphite full cells. The cell with GPI-5 separator displayed a relatively slight capacity fading, comparing to that of Celagrd 2400 separator. This result demonstrated that GPI-5 membrane was feasible for high performance

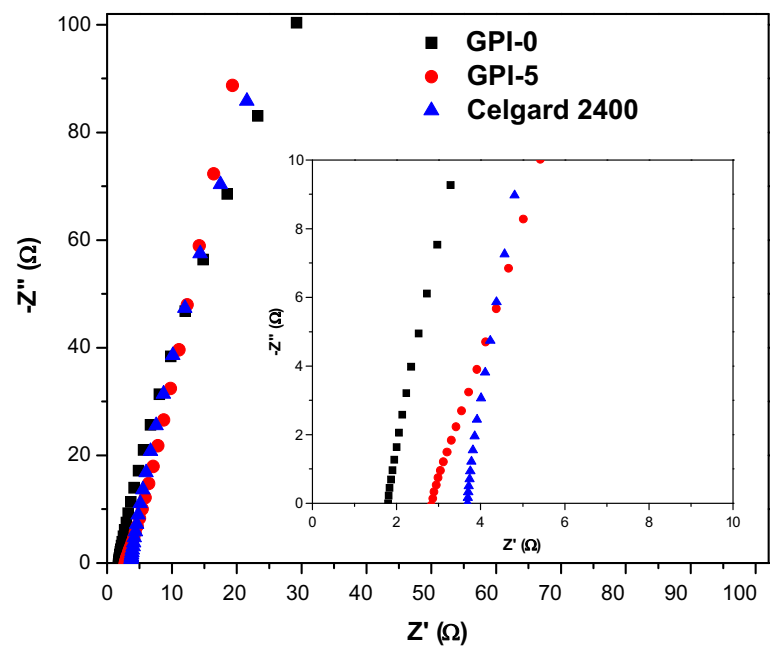

Fig. 8 Nyquist plots of the liquid electrolyte-soaked GF, GPI-5 membrane and Celgard 2400 separator.

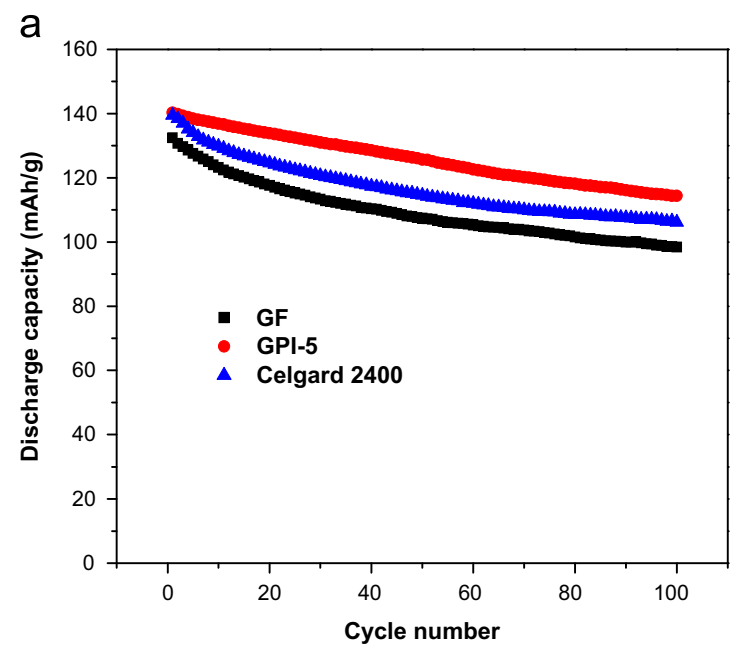

separator in LIB owing to their favorable interface characteristic and strong affinity for liquid electrolyte.

The rate ability performance of cells was essential for lithium ions battery, especially for high power battery. Fig. 10 depicted rate capability of the $\mathrm{LiFePO}_{4} / \mathrm{Li}$ cells from 2.8 to $4.2 \mathrm{~V}$ at different rates $(0.2 \mathrm{C} / 0.2 \mathrm{C}, 0.5 \mathrm{C} / 0.5 \mathrm{C} 1 \mathrm{C} / 1 \mathrm{C}$, $2 \mathrm{C} / 2 \mathrm{C}, 4 \mathrm{C} / 4 \mathrm{C}, 8 \mathrm{C} / 8 \mathrm{C})$, using $\mathrm{GPI}-5$ membrane and Celgard 2400 as separators. It was clearly observed that the cell with Celgard 2400 separator delivered specific capacity about $142 \mathrm{~mA} \mathrm{~h} \mathrm{~g}^{-1}$ at $0.2 \mathrm{C} / 0.2 \mathrm{C}$, and the capacity retention ratio is about $85 \%$ at $0.5 \mathrm{C} / 0.5 \mathrm{C}$ and $67 \%$ at $2 \mathrm{C} / 2 \mathrm{C}$, and then decrease rapidly to $38 \%$ at $8 \mathrm{C} / 8 \mathrm{C}$, respectively. In contrast, the cell using GPI-5 separator exhibited the initial capacity about $143 \mathrm{~mA} \mathrm{~h} \mathrm{~g}^{-1}$ at $0.2 \mathrm{C} / 0.2 \mathrm{C}$. Then the capacity retention ratio kept $89 \%$ at $0.5 \mathrm{C} / 0.5 \mathrm{C}$ and $72 \%$ at $2 \mathrm{C} / 2 \mathrm{C}, 48 \%$ at $8 \mathrm{C} / 8 \mathrm{C}$, respectively. The GF separator showed poor rate capability, only with a capacity of $21 \mathrm{~mA}$ $\mathrm{h} \mathrm{g}^{-1}$ at $4 \mathrm{C} / 4 \mathrm{C}$ (Fig. 10). The low rate performance of pristine GF could be closely related to the self-discharge of cells, and the reason was discussed later. In our case, cells with GPI-5 separator displayed much better rate capability

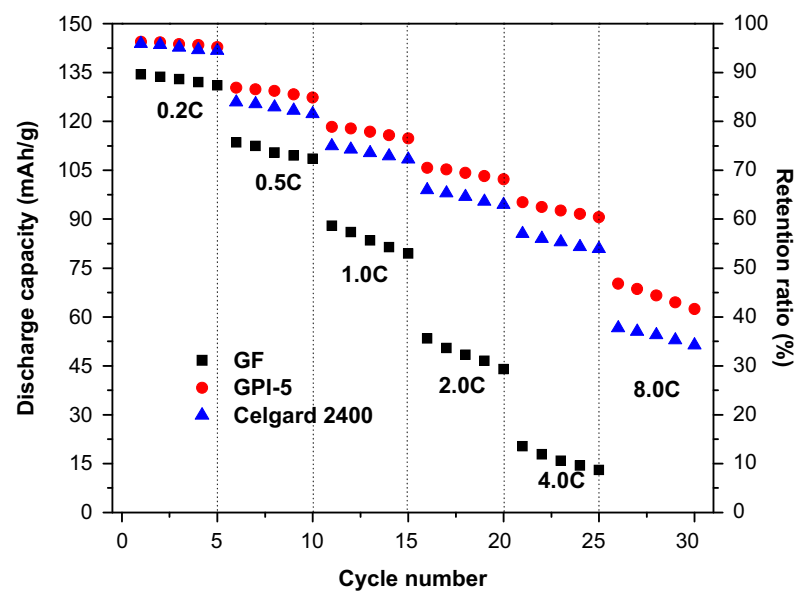

Fig. 10 Rate capability of the $\mathrm{LiFePO}_{4} / \mathrm{Li}$ cells using GF, GPI-5 and Celgard 2400 separator.

b

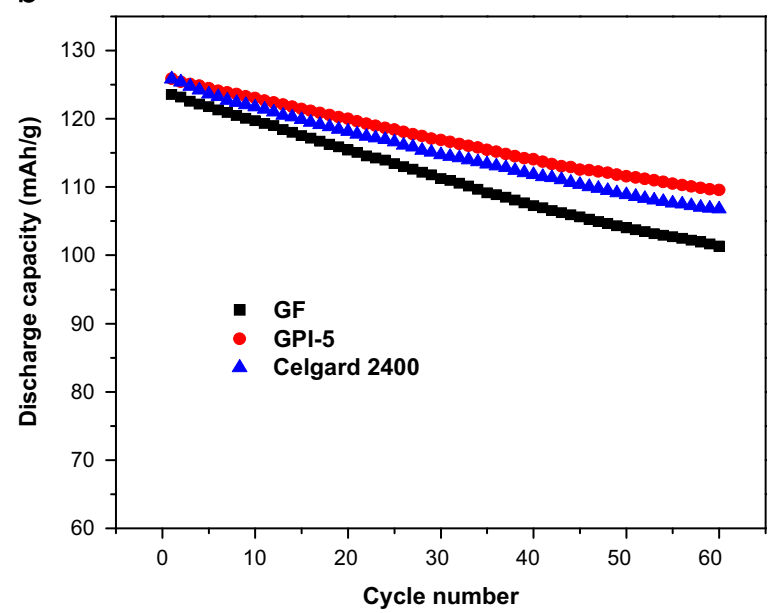

Fig. 9 Cycle performance of the $\mathrm{LiFePO}_{4} / \mathrm{Li}$ and $\mathrm{LiFePO}_{4} /$ graphite cells using GF, GPI and Celgard 2400 separator at room temperature. 


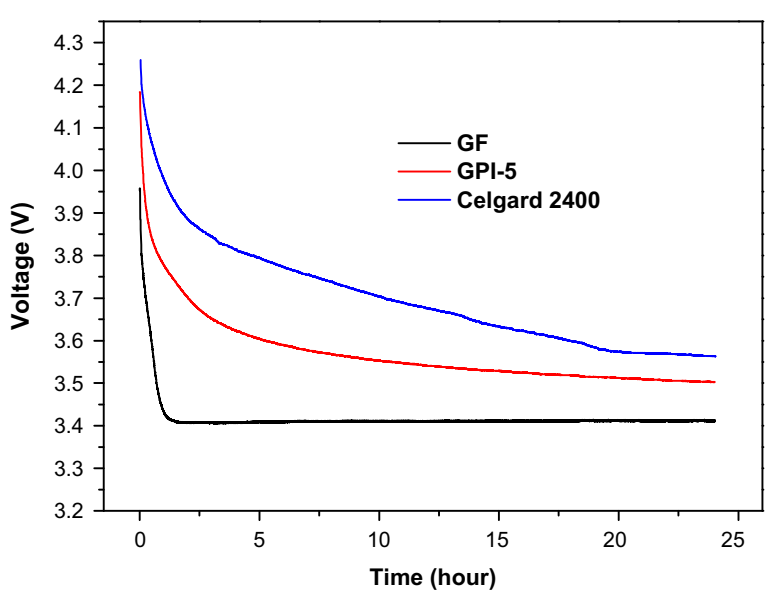

Fig. 11 Open-circuit voltage (OCV) retention test of the $\mathrm{LiFePO}_{4} /$ Li cells using GF, GPI-5 and Celgard 2400 separator.

than that of Celgard 2400. The superior rate performance was closely related to the more absorption of electrolyte and fast efficient ionic conduction in GPI-5 membranes, which could offer rapid lithium ion transport across the interface of electrodes and electrolyte in cell [32].

In order to evaluate the functional feature of separator in cells, the open-circuit voltage (OCV) retention was tested. The $\mathrm{LiFePO}_{4} / \mathrm{Li}$ cells with different separators were full charged at $4.2 \mathrm{~V}$, and then monitored the voltage variation in $24 \mathrm{~h}$. Fig. 11 showed the OCV retention results of cells with GF, GPI-5 and Celgard 2400 separator at room temperature. It was obvious that the Celgard 2400 separator displayed excellent insulation performance, compared with GF and GPI-5 separator. It was considered that the porosity and holes structure were important factors for insulation performance. The large scale pores, which was observed by the SEM images (Fig. 2), could be the reasons for the poor voltage retention of cells. It was notable that the composite membrane, GPI-5, showed a better insulation performance than pristine glass microfiber membrane, which demonstrated that the incorporation with polyimide was an effect way to improve its insulation property.

Furthermore, the OCV retention was a key indicator for self-discharge process of cells, and that process influenced other properties of cells. In Fig. 10, the cell with pristine glass microfiber separator showed poor rate capability, which was not matched its porosity and Gurley value results. The reason for that deviation could de due to self-discharge problem of cells. It was observed that the self-discharge problem was obvious in the glass microfiber film due to large pores (Fig. 11), and this problem became intensified when the film thickness reduced from $1 \mathrm{~mm}$ to $25 \mu \mathrm{m}$ (Supplementary SI. 5) or the temperature of cells increased to high level (Supplementary SI. 6). So, in the rate discharge tests, large current could cause the increasing of temperature inside the cell and intensify the self-discharge process, and that process made the cell unstable and resulted in the loss of discharging capacity. According to above discussion, it was considered that the intensified selfdischarge and unstable state of cell maybe the reason for the decreased rate capability of cell with glass microfiber separator.
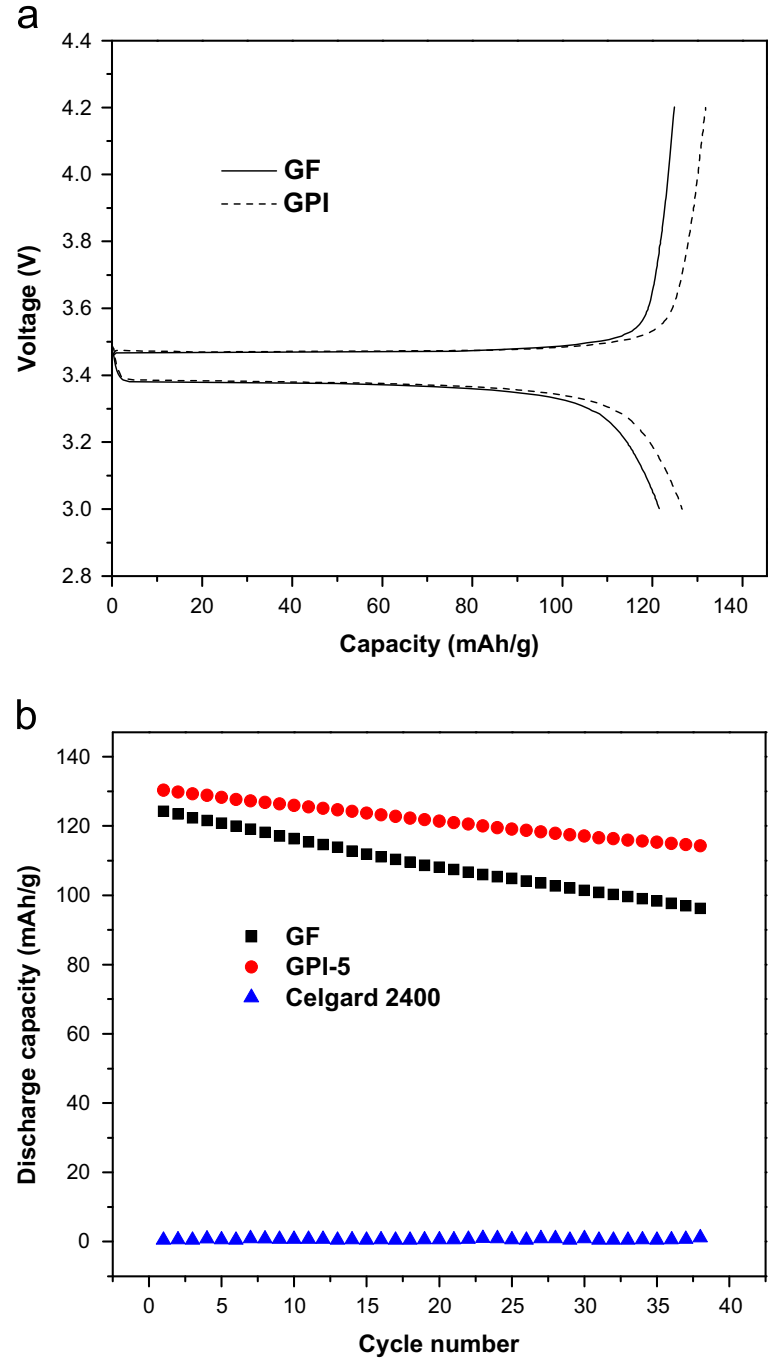

Fig. 12 The charge-discharge curves (a) and cycling stability (b) of the $\mathrm{LiFePO}_{4} / \mathrm{Li}$ cells with GF, GPI-5 and Celgard 2400 separator at an elevated temperature of $120^{\circ} \mathrm{C}$.

The battery performance at elevated temperature was crucial to cells's safety characteristic. The lithium ion cells using composite membrane as separator with LiBOB/PC as electrolyte was also investigated at an elevated temperature of $120{ }^{\circ} \mathrm{C}$. Fig. 12 depicted the charge-discharge curves and cycle performance with voltage ranging from $3.0 \mathrm{~V}$ to $4.2 \mathrm{~V}$ at a rate of $0.2 \mathrm{C} / 0.2 \mathrm{C}$ at $120{ }^{\circ} \mathrm{C}$. The cells using both GF and GPI-5 membrane as separator delivered the first discharge capacity of $124 \mathrm{~mA} \mathrm{~h} \mathrm{~g}^{-1}$ and $129 \mathrm{~mA} \mathrm{~h} \mathrm{~g}^{-1}$ for GF and GPI-5, respectively. Stable, smoothing plateau was observed in charge and discharge process for both GF and GPI-5 membranes, indicating a stable insertion/deinsertion reaction in LIB at the elevated temperature. The stable discharge behavior could be due to the incorporation of polyimide reducing the inhomogeneous large-sized pores and suppressed the self-discharge process. That process can also be corroborated in Fig. 12b, in which the cell with GPI5 showed a slower decay with the increasing cycle number. In addition, we tried to test the charge-discharge curve of cell with Celgard 2400 membrane as separator at that temperature. Unfortunately, the cell using Celgard 2400 separator exhibited a dramatic decline in discharge voltage 
with a negligible discharge capacity. This result suggested the thermal failure of separator resulting in internal shortcircuits in the cell [33]. Therefore, GPI-5 membrane was suitable for highly safe separator at the elevated temperature, which may be a potential separator for high power battery in future.

\section{Conclusions}

The composite membrane of glass microfiber and polyimide were prepared by dip coating process, where the polyimide coated on the surface of the glass microfiber and interconnected the glass microfiber, improving its porous structure and mechanical strength. The mechanical strength of membranes was enhanced from 1.1 MPa for pristine glass microfiber membrane with paper making process to $23.8 \mathrm{MPa}$ (GPI-20). It was demonstrated that the composite membrane showed excellent thermostability, with no obvious thermal shrinkage even at $200{ }^{\circ} \mathrm{C}$, while the Celgard 2400 membranes were melted. Moreover, the glass microfiber and composite membrane displayed a perfect flame retarding ability. The cell performance suggested that the composite membrane was an excellent candidate of high performance separator, according to the cycling performance and rate capability. It was noted that the cells with composite membrane as separator offered a reliable battery performance even at $120^{\circ} \mathrm{C}$, indicating that the composite membrane was a potential separator material for the future high power battery.

\section{Acknowledgments}

This work was supported by the National High Technology Research and Development Program of China (863 Program, No. 2013AA050905), the Key Technology Research Projects of Qingdao (No. 13-4-1-10-gx), the NSFC program (21271180), National Program on Key Basic Research Project of China (973 Program) (No. MOST2011CB935700), “135” Projects Fund of CAS-QIBEBT Director Innovation Foundation and the Instrument Developing Project of the Chinese Academy of Sciences (No. YZ201137). In addition, the authors thank The Qingdao Key Lab of Solar Energy Utilization and Energy Storage Technology.

\section{Appendix A. Supporting information}

Supplementary data associated with this article can be found in the online version at http://dx.doi.org/10.1016/ j.nanoen.2014.10.001.

\section{References}

[1] D. Linden, T.B. Reddy, Handbook of Batteries, third ed., McGraw-Hill, 2002.

[2] S.S. Zhang, J. Power Sources 164 (2007) 351-364.

[3] P. Arora, Z.M. Zhang, Chem. Rev. 104 (2004) 4419-4462.

[4] T.H. Cho, M. Tanaka, H. Ohnishi, Y. Kondo, M. Yoshikazua, T. Nakamura, T. Sakai, J. Power Sources 195 (2010) 4272-4277.

[5] J.M. Ko, B.G. Min, D.W. Kim, K.S. Ryu, K.M. Kim, Y.G. Lee, S.H. Chang, Electrochim. Acta 50 (2004) 367-370.

[6] M.H. Ryou, Y.M. Lee, J.K. Park, J.W. Choi, Adv. Mater. 23 (2011) 3066-3070.
[7] Q.S. Wang, P. Ping, X.J. Zhao, G.Q. Chu, J.H. Sun, C.H. Chen, J. Power Sources 208 (2012) 210-224.

[8] J.J. Zhang, L.P. Yue, Q.S. Kong, Z.H. Liu, X.H. Zhou, C.J. Zhang, S.P. Pang, X.J. Wang, J.H. Yao, G.L. Cui, J. Electrochem. Soc. 160 (2013) A769-A774.

[9] X.S. Huang, D. Bahroloomi, X.R. Xiao, J. Solid State Electrochem. 18 (2014) 133-139.

[10] H.J. Wang, T.P. Wang, S.Y. Yang, L. Fan, Polymer 54 (2013) 6339-6348.

[11] J. Ding, Y. Kong, P. Li, J.R. Yang, J. Electrochem. Soc. 159 (2012) A1474-A1480.

[12] W. Qi, C. Lu, P. Chen, L. Han, Q. Yu, R.Q. Xu, Mater. Lett. 66 (2012) 239-241.

[13] J. Lee, C.L. Lee, K. Park, I.D. Kim, J. Power Sources 248 (2014) $1211-1217$.

[14] J.L. Shi, H.S. Hu, Y.G. Xia, Y.Z. Liu, Z.P. Liu, J. Mater. Chem. A 2 (2014) 9134-9141.

[15] Y.S. Zhu, F.X. Wang, L.L. Liu, S.Y. Xiao, Y.Q. Yang, Y.P. Wu, Sci. Rep 3 (2013) 3187.

[16] Sh.H.S. Yousfani, R.H. Gong, I. Porat. Fibres Text. East. Eur. 2 (2012) 61-67.

[17] X.S. Huang, J. Power Sources 256 (2014) 96-101.

[18] I.A. Ronova, O.V. Sinitsyna, S.S. Abramchuk, A.Y. Nikolaeva, S. Chisca, I. Sava, M. Bruma, J. Supercrit. Fluid. 70 (2012) 146-155.

[19] J.H. Park, J.H. Cho, J.S. Kim, E.G. Shim, S.Y. Lee, Electrochim. Acta 86 (2012) 346-351.

[20] T.H. Nguyen, C. Wang, X. Wang, J. Memb. Sci. 342 (2009) 208-214.

[21] J.D. Xiao, L.G. Qiu, Y.P. Yuan, X. Jiang, A.J. Xie, Y.H. Shen, Inorg. Chem. Commun. 29 (2013) 128-130.

[22] Y.N. Sazanov, G.N. Fedorova, L.M. Shcherbakova, Thermochim. Acta 17 (1976) 119-127.

[23] B.Q. Tang, D.D. Cai, J. Sun, J.J. Wang, L.X. Dai, Polym. Composite. 34 (2013) 2076-2081.

[24] X.S. Huang, J. Hitt, J. Membr. Sci 425 (2013) 163-168.

[25] M. Kim, J.Y. Shon, Y.C. Nho, T.W. Lee, J.H. Park, J. Electrochem. Soc. 157 (2010) A31-A34.

[26] P. Raghavan, X.H. Zhao, C. Shin, D.H. Baek, J.W. Choi, J. Manuel, M.Y. Heo, J.H. Ahn, C. Nah, J. Power Sources 195 (2010) 6088-6094.

[27] K.S. Liu, X. Yao, L. Jiang, Chem. Soc. Rev. 39 (2010) 3240-3255.

[28] J.H. Kim, B.R. Min, J. Won, H.C. Park, Y.S. Kang, J. Memb. Sci. 187 (2001) 47-55.

[29] M.M. Rao, J.S. Liu, W.S. Li, Y. Liang, Y.H. Liao, L.Z. Zhao, J. Power Sources 189 (2009) 711.

[30] W. Jiang, Z.H. Liu, Q.S. Kong, J.H. Yao, C.J. Zhang, P.X. Han, G.L. Cui, Solid State Ionics. 232 (2013) 44-48.

[31] G.L. Ji, B.K. Zhu, Z.Y. Cui, C.F. Zhang, Y.Y. Xu, Polymer 48 (2007) 6415-6425.

[32] H.S. Jeong, D.W. Kim, Y.U. Jeong, S.Y. Lee, J. Power Sources 195 (2010) 6116-6121.

[33] F. Croce, M.L. Focarete, J. Hassoun, I. Meschini, B. Scrosati, Energy Environ. Sci. 4 (2011) 921-927.

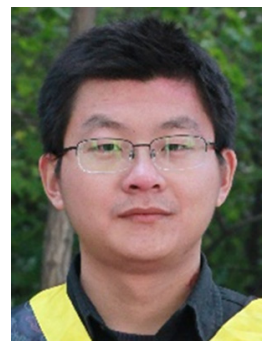

Bo Zhang received his Ph.D. degree in 2011 from the Harbin Institute of Technology(HIT). He joined the Qingdao Institute of Bioenergy and Bioprocess Technology (QIBEBT), Chinese Academy of Sciences as a research assistant in 2012. His current research focuses on materials and devices for lithium ion battery, including separator materials, electrode materials and transparent energy-storage devices. 


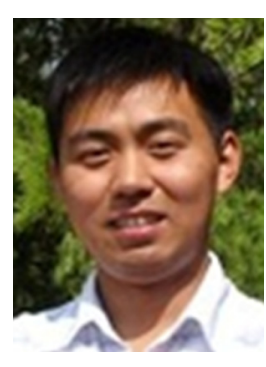

Qingfu Wang graduated from the Qingdao University of Science and Technology in 2009. He joined the Qingdao Institute of Bioenergy and Bioprocess Technology (QIBEBT), Chinese Academy of Sciences in 2009. His research was concentrated on polymer electrolyte and inflaming retarding materials.

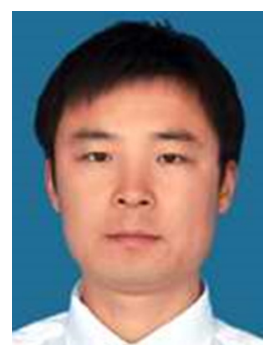

Jianjun Zhang graduated from the Qingdao University in 2011. His current research focuses on polymer materials and devices for lithium ion battery, including polymer electrolyte, separator materials and flexible battery devices.

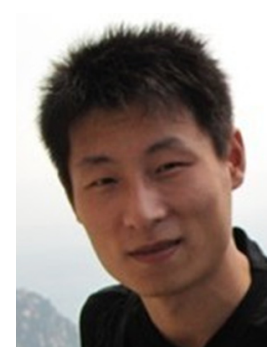

Guoliang Ding is a Chemical Engineer from lithium ion battery. He has been working in lithium ion battery assemble area for almost four years. He got his Masters degree in 2008, and now he is working in the field of new separator materials for sodium ion batteries.

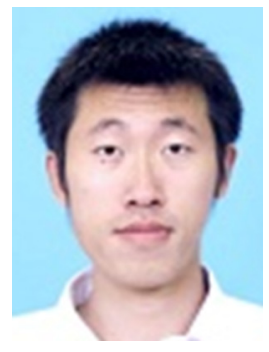

Gaojie Xu received his Masters degree in 2012. He has been working in Quality control of lithium ion battery for two years. He is young, but a seasoned engineer for lithium ion battery.

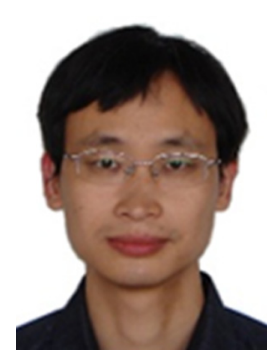

Zhihong Liu was born in 1975 . He received his Ph.D. degree in 2005 from the Changchun Institute of Applied Chemistry, Chinese Academy of Sciences. From 2005 to 2008, he had worked at Max-Planck-Institute for Polymer Research as a postdoctoral scientist. He joined the Qingdao Institute of Bioenergy and Bioprocess Technology (QIBEBT), Chinese Academy of Sciences as a research assistant in 2009

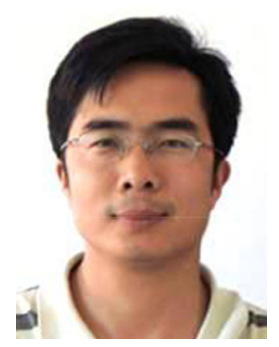

Guanglei Cui obtained his Ph.D. degree at the Institute of Chemistry, CAS, in 2005. From 2005 to 2009, he had worked at MaxPlanck-Institute for Polymer Research and Max-Planck-Institute for Solid State research as a postdoctoral scientist on Ener. Chem. Project. Then he joined in the Qingdao Institute of Bioenergy and Bioprocess Technology, CAS as full professor from 2009. Prof. Cui has published 90 papers on peerreviewed journals of Adv. Mater., Angew. Chem. Int. Ed., Coordin. Chem. Rev., Energy Environ. Sci., Chem. Mater., most of which have been indexed by $\mathrm{SCl}$. His research interests include low-cost and highly efficient energy-storage materials, electrode materials and novel energy devices including lithium ion batteries, super-capacitors and perovskite solar cells. 